\title{
SCHNITZER, Claudia, HÖLSCHER, Petra, Eine gute Figur machen. Kostüm und Fest am Dresdner Hof
}

\section{Claire Gantet}

\section{OpenEdition}

\section{Journals}

Édition électronique

URL : http://journals.openedition.org/ifha/1279

DOI : $10.4000 /$ ifha. 1279

ISSN : 2198-8943

\section{Éditeur}

IFRA - Institut franco-allemand (sciences historiques et sociales)

\section{Référence électronique}

Claire Gantet, "SCHNITZER, Claudia, HÖLSCHER, Petra, Eine gute Figur machen. Kostüm und Fest am Dresdner Hof », Revue de l'IFHA [En ligne], Date de recension, mis en ligne le 01 janvier 2001, consulté le 22 septembre 2020. URL : http://journals.openedition.org/ifha/1279 ; DOI : https://doi.org/10.4000/ ifha. 1279

Ce document a été généré automatiquement le 22 septembre 2020.

(C)IFHA 


\title{
SCHNITZER, Claudia, HÖLSCHER, Petra, Eine gute Figur machen. Kostüm und Fest am Dresdner Hof
}

\author{
Claire Gantet
}

1 Ce livre est le catalogue d'une exposition sur la fête et le costume à la cour de Dresde au XVIIIe s., réalisée du 10 septembre au 3 décembre 2000 d'après les fonds du "Salon d'Estampes » de Dresde. D'emblée, ce cabinet (dont C.S. brosse l'histoire), fondé en 1720 et structuré non en collections d'art mais autour des sciences, servit à la fois de bibliothèque et de cabinet d'antiquités, de médailles et d'histoire naturelle. Mais le dessein documentaire et didactique fut soutenu par l'ambition de représentation de la dynastie. À sa fondation, il tint lieu de premier " musée d'art graphique » en Allemagne, et, jusqu'en 1756, il accueillit 130000 gravures et 15802 dessins. On comprend dès lors la richesse des représentations de fêtes et des esquisses de costumes révélées par ce catalogue. "Faire bonne figure » était au XVIIIe s. la condition requise pour réussir à une cour princière ; comme le rappelle C.S. (" Entree »), cela signifiait choisir un habillement adapté (l'habit) et adopter un comportement approprié (l'habitus) ; le costume servait d'indicateur du rang de l'individu dans le système curial, de sa proximité vis-à-vis du prince. À Dresde, à partir du XVIIIe s., des figurines, c'est-àdire des mannequins (d'abord en bois, puis en porcelaine, ou en cire, avec des membres mobiles) coiffés et habillés d'après la dernière mode française, étaient envoyées à des fins de représentation en Angleterre et dans les grandes villes européennes, contribuant à diffuser encore la mode française. Allant jusqu'à modifier les rites funéraires marquant la différence des " deux corps du roi " (Ernst Kantorowicz), Auguste le Fort fit fabriquer de son vivant même des mannequins à ses traits. Le moment par excellence de démonstration était bien sûr les fêtes princières, souvent conçues d'après les relations de fêtes rédigées pour les cérémonies de Louis XIV. L'ouvrage, composé d'une première partie d'articles (p. 1-99) et d'une deuxième de catalogue (p. 100-313), développe ces différents aspects : A. MIKSCH souligne la fonction de haut maréchal des cours dans l'ordonnancement des fêtes ainsi que de la vie théâtrale et musicale ; J. BÄUMEL montre le rôle de représentation de la salle d'armes 
depuis le déplacement de la résidence de Wittenberg à Dresde en 1547 ; K. SCHLECHTE évoque les costumes et les décorations du théâtre de cour ; B. JAHN expose les principes de représentation du théâtre musical baroque, la passion et le décorum, qu'il explique par l'importance attachée aux signes et aux gestes du corps ; H. SCHUCKELT et G.J.M. WEBER mettent en lumière l'autre source d'inspiration, à côté de la mode française, la civilisation turque, admirée en Saxe, à la différence des autres États allemands où elle fait figure de repoussoir. On retiendra surtout de ce beau catalogue (où les questions qui intéressent avant tout les historiens, l'existence ou non d'un absolutisme à la cour de Dresde, la réception des fêtes et des modes courtisanes, et les formes et l'extension du mimétisme social, ne sont guère traitées) sa très belle illustration. 